\title{
Politics on Campus: Why do Students Join Campus Politics in Islamabad?
}

\author{
Akhlaq Ahmad* \\ Department of Sociology, International Islamic University, Islamabad, Pakistan.
}

Received: June 14, 2020

Published Online: October 30, 2020

\begin{abstract}
Education has been an extensively researched area as an important resource of political participation across the globe. However, politics on campus has been an under-researched in South Asia including Pakistan. This study was set forth to explore the factors responsible for the involvement of students in politics at the campus. The present study was conducted under positivist epistemology in three randomly selected public sector universities in Islamabad city, Pakistan. A sample of 396 proportionately selected male students was drawn from the selected universities. A self-constructed questionnaire was employed in the survey to collect the data. Alpha reliability of the subscales was calculated and found appropriate to use. Factors including peer suggestion, ethnic affiliation, academic environment, political culture, political socialization, perceived status, and power deficit were tested to find out their association. The Pearson correlational analysis confirmed the association of all the variables. It can be concluded that all the above seven variables are persuading students to join politics on campus and participate in political activities.
\end{abstract}

Keywords: Student Politics, Peer Suggestion, Ethnic Affiliation, Academic Environment, Perceived Status, Power Deficit.

\section{Introduction}

Education has traditionally been found very important in explaining political behaviour and overall political participation of citizens including youth. A stream of researchers for instance (Miller et al., 1985; Verba \& Nie, 1987; Dalton, 1988; Verba et al., 1995; Peterson, 1990) has substantially emphasized the role of education in predicting, promoting, and perpetuating political behaviour and political activities. Another stream of researchers considered socioeconomic status as an important factor for political engagement (Wolfinger \& Rosenstone, 1980; Dalton, 1982; Wolsfeld, 1986; Verba et al., 1995). These researchers looked at education as one of the factors promoting political participation in masses in society. They considered education as one of the vital resources ensuring political socialization and resultant participation in the political realm. However, they rarely included educational institutions as unique sites for the research.

Higher educational institutes including university are a very dynamic platform for personal, professional, and career aspirations. It is one of the powerful social agents of socialization. It helps students sharpen their social, cultural, economic, and political skills. Researchers like Finlay \& Flanagan (2009) found that students' participation in community-related work 
increased as they joined higher education. Their civic engagement improved considerably. Similarly, Galston (2001) and Beaumont et al. (2006) noted that students of the university were more enthusiastic to actively participate in community and other voluntary work. They have developed a strong civic sense. Different activities in and out of the classroom, discussion with class fellows, and other co-curricular and extra-curricular activities like sports are important for the political socialization of students, which in the long run promotes their participation in politics and the related activities. These skills enhanced their interest in the political activities and improved their participation (McMillan \& Harriger, 2002; Colby et al., 2010; Einfeld \& Collins, 2008; Kahne \& Middaugh, 2008; Finlay \& Flanagan, 2013; Aqsa et al., 2017).

Higher education also provides opportunities for interaction with diverse group of fellows from different social, cultural, economic, religious, and political backgrounds (Yeoh, 2006; Khan \& Rehman, 2018). Common interests, ideologies, ethnicities, and problems at campus provide strong bases for interaction. Students also are cognizant of their social network and cultural capital. Researchers for example (Putnam, 2000; Price, Cappella \& Nir, 2002; Barabas \& Jerit, 2004; Huckfeldt et al., 2004) clearly and strongly emphasized the importance and role of peer in shaping political behavior. Diversity of interaction is very vital for co-existence. Flow of information, the plurality of ideology, results in developing political attitudes and increasing political participation. Researchers like (Cigler \& Joslyn, 2002; Marschall \& Stolle, 2004; Mutz \& Mondak, 2006) have also pointed out the importance of social networks in the increased flow of information and political mobilization. Peer association has been found to have a strong impact on political activities and the provision of channels to express political views. However, Teorell (2003) has accentuated the nature of relationships, time spent, and level of formality. These factors can undermine the quality of discussion, exchange of information, and the flow of political information.

The campus is a place rich with diverse ethnic and linguistic groups. This multi-ethnic environment sometimes is discouraging for some ethnic or linguistic group and provides them fewer resources and opportunities. These ethnic/ linguistic groups may have different political attitudes and sometimes conflicting. Which in turn brings them more criticism and discrimination. However, this feeling of discrimination and isolation is fetched with a possibility to group together with the students of the same ethnicity or language. Researchers for instance (Baltzell, 1976; Klobus-Edwards et al., 1978) have explored the experiences of black people in American society in general and in universities in particular. They have pointed out that students with similar ethnic/racial identities were more often connected and shared with each other. They often experienced prejudice, which pushed them to connect to each other and share strategies to deal with that. Discrimination, discouragement, prejudice, deprivation, isolation, and stigmatization become the strong bases for political participation for these individuals and/or groups.

The academic environment is one of the most crucial factors influencing students in multiple ways. The availability of political groups on campus, academic policies, curriculum, and other administrative arrangements have both negative and positive impacts and resultant political consequences. Researchers in this field like (Altbach, 1968; Berghe, 1973; Jayaram, 1979; Altbach, 1993) have discussed university policies, flagging conditions at campus, corruption, malpractices, poor administrative arrangement, and lack of facilities amongst the reasons for students' political activism. Students feel pressurized to stand against these odds and participate in all those activities including protests and agitation. Connell et al. (1981) highlighted a very important factor that indirectly pushes students to join politics and participate in political 
activities. She narrated that authority sometimes puts restrictions on political activities on campus and in some cases penalised students and teachers who were found guilty. This action propels staff and students both to actively take part in banned activities.

Some researchers for instance Berghe, (1973) and Rodriguez \& Routh (1989) have explored that demographic variables were responsible for the political participation of students. They explained that students were different areas particularly the rural areas faced difficulties on campus. This varied experience may push them to take part in politics. The availability of different political groups of students is one of the major reasons to join campus politics. These groups through study circles, political information, political campaigns, protests, agitations, and political training are providing a conducive environment for students to join different social groups and participate in the politics.

Political socialization of the students plays a very vital role. It has been extensively researched that students exhibit the political attitudes and behaviour they learned from their parents. Early researchers of political socialization for instance (Adorno et al., 1950; Campbell et al., 1954; Mazo \& Hess, 1968; Kraut \& Lewis, 1975) were of the view that youth carried the political attitudes of their parents. They emphasized the role of parents in the socialization process of their off springs. They also supported the generational continuity of political learning in the active participants in politics at the campus. They endorsed the idea that parents transport their political attitudes, behaviours, knowledge, values, and beliefs directly to children (Keniston, 1967). However, later researches did not find evidence to support the suppositions of the previous studies and researchers (Flacks,1967; Thomas, 1971). Nonetheless, parents have a very strong influence on their children and positively affect their attitudes and behaviours including those related to politics.

Status and power deficit are very important aspects of human life. Everyone at some point in time experiences at least the one (Turner \& Stets, 2005). Students from different socioeconomic backgrounds join the campus. They come across with different lifestyles, fashions, and other experiences. Students from the urban setting, middle class, educated family background, well exposed, technologically equipped can undermine the students from a rural and modest backgrounds. This social status cleavage results in status and power deficit. The researches have very loudly demonstrated that politics is one of the most important tools to enhance status and power. Students for the sack of excitement, impression management, and to impress their fellows join political activities. The notions of traditional masculinity also coincide with status and power deficit and push students to join politics. Political activism at campus gives prominence, exposure, opportunities for interaction, and well established social networks and capital (Loader et al., 2015).

The scholarship on politics at campus indicates different factors motivating/pushing students to join politics or participate in political activities. These factors include demographic, social, cultural, economic, and political. This scholarship documents education as one of the pivotal resources for political participation. It also highlights the socio-economic status of students' family as being significant. The literature mentions that peer interaction is of prime importance in shaping up political attitudes and behaviours among students. The cited studies spotlighted ethnic/linguistic affiliation and its contribution to political involvement of students at the campus. The research underlines academic culture, political culture of campus as one of the major factors responsible for students' political participation. The literature also draws its attention to the role of parents in inculcating political norms and values to children. The cited 
literature is dominantly the western experience and enumeration of different and diverse studies. The present study endeavours to incorporate all the above-discussed factors to theoretically align with the current scholarship on politics on campus.

The present study combines all the above-discussed factors to see which factor/s motivates students at campus to join politics and participate in political activities. The study also incorporates two more variables, status and power deficit along with variables derived from established research scholarship. This set of variables would be a contribution of this research to the existing body of research and knowledge on student politics on campus and is the first of its kind in Pakistan.

\section{Materials and Methods}

\subsection{Participants}

For this study, a sample of 396 male students enrolled in different academic programs (BS, MA/MSC, MS, PhD) in three randomly selected public sector universities of Islamabad- Quide-Azam university, Federal Urdu university and International Islamic university, was recruited proportionately. Selection of the public sector universities ensures representation of students from across Pakistan. Presence of different political wings of students in the public sector universities is also an important reason for their inclusion. Male students generally take active part in politics and political activities particularly in public sector universities. That is why this sample includes only male students enrolled in public sector universities. Students enrolled in the BS program constituted 50\% $(\mathrm{n}=198)$ followed by MA/MSC 38\% $(\mathrm{n}=151)$ and $12 \%(\mathrm{n}$ $=47)$ in MS/MPhil. An overwhelming majority of the participants' i.e. $90.2 \%(n=367)$ were residing either in university or private hostels. The participants of this study were living mostly in joint/extended family i.e. $75 \%(n=297)$. The majority of the participants placed them in the middle class. Participants $70 \%(\mathrm{n}=280)$ confirmed their affiliated with different political parties. Participants $22.5 \%(\mathrm{n}=89)$ considered them conservative, $42.4 \%(\mathrm{n}=168)$ moderate and $28.6 \%(\mathrm{n}=113)$ liberal.

\subsection{Procedure}

The questionnaires were distributed among the participants during university time. The participants were briefed about the purpose of the study. Informed consent was taken from every student in written form. The participants were assured of the confidentiality of the information obtained. They were also briefed that they can quit the survey any time they want. All the participants voluntarily joined the study.

\subsection{Measures}

A self-constructed questionnaire consisting of subscales was administrated to collect the data. The measures used five-point Likert type scale where strongly disagree was coded as 1 while strongly agree was coded as 5. Peer suggestion has 13 statements and points out the motivation/persuasion by the peer to joint politics. Alpha reliability of this variable was 0.77 . Ethnic affiliation has 10 statements and covers the ethnic/linguistic ties and their role in joining political activities. It has alpha reliability 0.69. Academic environment on campus has 15 statements and asks for the opportunities to participate in discussions, debates, and volunteering. Alpha reliability of this variable was 0.74 . Political culture on the campus has 10 
statements and denotes range of political activities and participation. It has alpha reliability 0.81. Political socialization with 7 statements describes the internalization of different political activities. Alpha reliability of this variable was 0.65 . Power deficit has 11 statements and indicates the perceived powerlessness in comparison with other fellows. It has alpha reliability .85. Status deficit with 6 statements describes perceived position in the group of fellows. It has alpha reliability 0.75 .

\section{Results and Discussion}

The analysis shown in table-1 indicates the Pearson $\mathrm{R}$ correlational of variables. It illustrates that all the study variables are strongly and positively associated with each other. The results are significant at .001 level. The analysis also points out that all the variables tested in this study to find out the factors motivating students in the campus to participate in politics and political activities are significant in predicting political participation.

The study was planned to find out the factors persuading students to participate in politics at the campus. Peer suggestion appears to be one of the important factors motivating students to participate in politics at the campus. Peer plays a very influential role in the overall socialization of students including political involvement. The informality of relationships, time spent with each other, and frequency of interaction makes relations stronger. It has been found that strong social networks and informal relationships are very much helpful for political information and mobilization (Marschall \& Stolle, 2004). Frequency of interaction and time spent with each other is providing an opportunity to discuss different personal, social, cultural, economic, and political issues (Cigler \& Joslyn, 2002; Putnam, 2002; Teorell, 2003; Mutz \& Mondak, 2006). Students at the campus interact with fellows, friends, teachers, and administration. This diverse interaction helps them develop long-term relationships. They also have to experience different views, which become an important source of information. Students with different sociopolitical backgrounds help each other to be politically tolerant and learn the value and importance of co-existence (Eveland \& Scheufele, 2000; Huckfeldt et al., 2004). Living in a hostel with students from different social, cultural, economic, religious, and political backgrounds is also helpful in developing political attitudes in students.

Ethnic identities are powerful predictors of political participation. Students of similar ethnic and linguistic backgrounds develop the sense of group identity among them. Research has clearly demonstrated that this interaction is very helpful in the flow of information and political knowledge. The campus at Islamabad is home to members of multiple ethnic and linguistic groups including Pashtuns, Punjabis, Sindhis, Baloch's, Galgit's, and Kashmiris. This multiplicity is of prime importance in terms of developing political attitudes and behaviours. These groups safeguard their interests and persuade their members for active participation in all those related activities. They are also actively engaged in political bargaining with university administration.

The study illustrates that the academic environment of the campus directly and indirectly, influences students' political behaviours. The academic environment is a complex of student, teacher, administration, curriculum, and policies. Public sector universities are facing many problems including financial, bureaucratic, and governance issues. These academic, cocurricular, and extra-curricular problems are one of the major sources and indicators of political participation. Students have a very keen interest in campus issues and try their best to overcome these. Different levels of expectation of students also motivate students to take part in political 
activities at the campus. The availability of various political groups at campus is another important source of political participation.

The political culture of the campus and political socialization of students are very crucial indicators of political participation. The presence of political activities on campus is motivating them directly to participate in politics. Political groups are engaging students in study circles, protests, campaigns, agitation, and many other political activities. Political activities at the campus are a source of political information, knowledge, and interest and all these are strong predictors of political participation. The findings of this study also confirmed that the political culture of the campus and political socialization are strongly and positively associated with each other and are sources of political participation of students at the campus.

The perceived power and status deficit were two new factors incorporated in this study keeping in view the socio-cultural and political realities of Pakistani society. There is a dearth of academic literature on the perceived status and the power deficit among university students. Politics is one of the important spheres of power and authority. Involvement in politics in general and on campus in particular breeds benefits including strong social networks, capital, and sometimes due/ undue favours. Members of the political groups enjoy prestige and often hold positions in their political groups. They have the opportunity to interact with faculty, administration and can assert when it is possible and/or necessary. This relatively high status and assertion of power can impress and motivate other students to take part in the group politics and the political activities on campus. Students also learn from their families, neighbours, community, and society that politics can push their social position upwards. Students from lower socio-economic status can also found political a ladder to enhance their social status (Brass \& Krackhardt, 2012).

Table 1: Pearson R correlational analysis of Study Variables $(\mathrm{N}=396)$

\begin{tabular}{|c|c|c|c|c|c|c|c|}
\hline Variables & 1 & 2 & 3 & 4 & 5 & 6 & 7 \\
\hline 1. Peer Suggestion & 1 & & & & & & \\
\hline 2. Ethnic Affiliation & $.55^{* *}$ & 1 & & & & & \\
\hline 3. Academic Envir. & $.53^{* *}$ & $.47 * *$ & 1 & & & & \\
\hline 4. Pol. Culture & $.46^{* *}$ & $.46^{* *}$ & $.60 * *$ & 1 & & & \\
\hline 5. Pol. Socialization & $.44 * *$ & $.40 * *$ & $.40 * *$ & $.49 * *$ & 1 & & \\
\hline 6. Power Deficit & $.34 * *$ & $.46^{* *}$ & $.39 * *$ & $.57 * *$ & $.34 * *$ & 1 & \\
\hline 7. Status Deficit & $.47 * *$ & $.27 * *$ & $.29 * *$ & $.29 * *$ & $.17 * *$ & $.55^{* *}$ & 1 \\
\hline
\end{tabular}
**p $<.001$

\section{Conclusion}

The findings demonstrated that students at campus join politics or political activities because they are under the strong influence of their peers and the ethnic groups present on the campus of the university. Ethnic affiliation to the groups is powerfully endorsing their political participation. The academic environment of the campus, and issues faced in the co-curricular and extra-curricular activities is another strong tenacious factor for them to join the political groups at the campus. Political culture and political socialization are also influencing the students to take part in the university level politics. The perceived status and power deficit also persuade the students to participate in the politics on campus. 


\section{References}

Adorno, T. W., Frenckel-Brunswik, E., Levinson, D. J. \& Sanford, R. $\quad$ N. (1950). The authoritarian personality. Harper.

Altbach, P. G. (1968). Student politics in Bombay (Vol. 3). Asia Publishing House.

Altbach, P. G. (1993). The dilemma of change in Indian higher education. Higher Education, 26(1), 3-20. https://doi.org/10.1007/BF01575104

Aqsa, K., Riaz, W. \& Saleem, Z. (2017). The effectiveness of games in English language learning at elementary level in government schools. Liberal Arts and Social Sciences International Journal (LASSIJ), $1(2), \quad$ 12-23. https://doi.org/10.47264/idea.lassij/1.2.2

Baltzell, E. D. (1976). The protestant establishment revisited. The American Scholar, 45(4), 499-518.

Barabas, J., \& Jerit, J. (2004). Redistricting principles and racial representation. State Politics \& Policy Quarterly, 4(4), 415-435. https://www.cambridge.org/core/journals/statepolitics-and-policy-quarterly/article/abs/redistricting-principles-and-racialrepresentation/752A799B3254F6B9856FFCDC8F3E5A74

Beaumont, E., Colby, A., \& Ehrlich, T. Torney-Purta, 1. (2006). Promoting political competence and engagement in college students. Journal of Political Science Education, 2(3), 249-170. https://doi.org/10.1177/153244000400400404

Brass, D. J., \& Krackhardt, D. M. (2012). Power, politics, and social networks in organizations. In Politics in organizations: Theory and research considerations. Rutledge. https://www.taylorfrancis.com/chapters/edit/10.4324/978020319742422/power-politics-social-networks-organizations-daniel-brass-david-krackhardt

Campbell, C., \& Converse, P. (1954). Miller, and Stokes. 1960. The American Voter.

Cigler, A. J., \& Joslyn, M. (2002). Groups, social capital, and democratic orientations. Interest Group Politics. CQ Press.

Colby, A., Beaumont, E., Ehrlich, T., \& Corngold, J. (2010). Educating for democracy: Preparing undergraduates for responsible political engagement (Vol. 19). John Wiley.

Connell, R. W., Dowsett, G. W., Kessler, S., \& Ashenden, D. J. (1981). Class and gender dynamics in a ruling-class school. Interchange, 12(2-3), 102-117. https://doi.org/10.1007/BF01192110

Dalton, R. J. (1982). The pathways of parental socialization. American Politics Quarterly, 10(2), 139-157. https://doi.org/10.1177/004478082010002001

Dalton, R. J. (1988). Citizen politics in Western democracies: Public opinion and political parties in the United States, Great Britain, West Germany, and France. Chatham House.

Einfeld, A., \& Collins, D. (2008). The relationships between service-learning, social justice, multicultural competence, and civic engagement. Journal of College Student Development, 49(2), 95-109. https://doi.org/10.1353/csd.2008.0017

Eveland Jr, W. P., \& Scheufele, D. A. (2000). Connecting news media use with gaps in knowledge and participation. Political Communication, 17(3), 215-237. https://doi.org/10.1080/105846000414250

Finlay, A. K., \& Flanagan, C. (2013). Adolescents' civic engagement and alcohol use: Longitudinal evidence for patterns of engagement and use in the adult lives of a British cohort. Journal of Adolescence, 36(3), 435-446. https://doi.org/10.1016/j.adolescence.2013.01.006 
Flacks, R. (1967). The liberated generation: An exploration of the roots of student protest. Journal of Social Issues, 23(3), 52-75. https://doi.org/10.1111/j.15404560.1967.tb00586.x

Galston, W. A. (2001). Political knowledge, political engagement, and civic education. Annual Review of Political Science, 4(1), 217-234. https://doi.org/10.1146/annurev.polisci.4.1.217

Huckfeldt, R., Mendez, J. M., \& Osborn, T. (2004). Disagreement, ambivalence, and engagement the political consequences of heterogeneous networks. Political Psychology, 25(1), 65-95. https://doi.org/10.1111/j.1467-9221.2004.00357.x

Jayaram, N. (1979). Sadhus no longer: Recent trends in Indian student activism. Higher Education, 8(6), 683-699. https://doi.org/10.1007/BF00215990

Kahne, J., \& Middaugh, E. (2008). High quality civic education: What is it and who gets it? Social Education, 72(1),

34-39. https://www.socialstudies.org/system/files/publications/articles/se 720134.pdf

Keniston, K. (1967). The sources of student dissent. Journal of Social Issues, 23(3), 108-137. https://doi.org/10.1111/j.1540-4560.1967.tb00589.x

Khan, N. U. \& Rehman, A. U. (2018). National character and leadership in Pakistan: Challenges and response. Pakistan Journal of Criminology, 10(2), 57-71.

Klobus-Edwards, P., Edwards, J. N., \& Klemmack, D. L. (1978). Differences in social participation: Blacks and whites. Social Forces, 56(4), 1035-1052. https://doi.org/10.2307/2577509

Kraut, R. E., \& Lewis, S. H. (1975). Alternate models of family influence on student political ideology. Journal of Personality and Social Psychology,31(5), 791-800. https://doi.org/10.1037/h0076688

Loader, B. D., Vromen, A., Xenos, M. A., Steel, H., \& Burgum, S. (2015). Campus politics, student societies and social media. The Sociological Review, 63(4), 820-839. https://doi.org/10.1111/1467-954X.12220

Marschall, M. J., \& Stolle, D. (2004). Race and the city: Neighbourhood context and the development of generalized trust. Political Behaviour, 26(2), 125-153. https://doi.org/10.1023/B:POBE.0000035960.73204.64

Mazo, E., \& Hess, S. (1968). Nixon: A political portrait (Vol. 75, No. 8077). Harper \& Row.

McMillan, J., \& Harriger, K. (2002). College students and deliberation: A benchmark study. Communication Education, 51(3), 237-253. https://doi.org/10.1080/03634520216518

Miller, K. A., Kohn, M. L., \& Schooler, C. (1985). Educational self-direction and the cognitive functioning of students. Social Forces, 63(4), 923-944. https://doi.org/10.2307/2578599

Mutz, D. C., \& Mondak, J. J. (2006). The workplace as a context for cross-cutting political discourse. The Journal of Politics, 68(1), 140-155. https://doi.org/10.1111/j.14682508.2006.00376.x

Peterson, S. A. (1990). Political behaviour: Patterns in everyday life (Vol. 177). SAGE.

Price, V., Cappella, J. N., \& Nir, L. (2002). Does disagreement contribute to more deliberative opinion? Political Communication, 19(1), https://doi.org/10.1080/105846002317246506

Putnam, R. D. (2000). Bowling alone: America's declining social capital. In: Culture and politics (pp. 223-234). Palgrave Macmillan. https://doi.org/10.1007/978-1-349$\underline{62397-6 \_12}$

Rodriguez, C. M., Routh, D. K. (1989). Depression, anxiety and attributional style in learning 
disabled and non-learning disabled children. Journal of Clinical Child Psychology, 18, 299-304. https://doi.org/10.1207/s15374424jccp1804_2

Teorell, J. (2003). Linking social capital to political Participation: Voluntary associations and networks of recruitment in Sweden. Scandinavian Political Studies, 26(1), 49-66. https://doi.org/10.1111/1467-9477.00079

Thomas, L. E. (1971). Political attitude congruence between politically active parents and college-age children: An inquiry into family political socialization. Journal of Marriage and the Family, 33(2), 375-386. https://doi.org/10.2307/349425

Turner, J. H., \& Stets, J. E. (2005). The sociology of emotions. Cambridge University. https://doi.org/10.1017/CBO9780511819612

Van den Berghe, P. L. (1973). Power and privilege at an African university. Transaction.

Verba, S., \& Nie, N. H. (1987). Participation in America: Political democracy and social equality. University of Chicago. https://doi.org/10.2307/j.ctv1pnc1k7

Verba, S., Schlozman, K. L., \& Brady, H. E. (1995). Voice and equality: Civic voluntarism in American politics. Harvard University.

Wolfinger, R. E., \& Rosenstone, S. J. (1980). Who votes? Yale University.

Wolsfeld, Gadi. (1986). Political action repertoires: The role of efficacy. Comparative Political Studies, 19(1), 104-129. https://doi.org/10.1177/0010414086019001005

Yeoh, E. K. K. (2006). Ethnic coexistence in a pluralistic campus environment. Geo Journal, 66(3), 223-241. https://doi.org/10.1007/s10708-006-9026-Z 